\begin{tabular}{|c|c|c|}
\hline PKS & REVISTA DE GEOGRAFIA & OJS \\
\hline $\begin{array}{l}\text { PUBLIC } \\
\text { KNOWLEDGE } \\
\text { PROJECT }\end{array}$ & $\begin{array}{c}(\mathrm{RECIFE}) \\
\mathrm{http} / / \text { www.revista.ufpe.br/revistageografia }\end{array}$ & $\begin{array}{l}\text { OPEN } \\
\text { JOURNAL } \\
\text { SYSTEMS }\end{array}$ \\
\hline
\end{tabular}

\title{
ANÁLISE DA APLICAÇÃO DA CARTOGRAFIA GEOMORFOLÓGICA BRASILEIRA NA PRODUÇÃO ACADÊMICA DE 2006 A 2016
}

\author{
Johana Maiy Alecrim Alves Gomes ${ }^{1}$, Maria Luisa da Fonseca Pimenta ${ }^{2}$, Therence Paoliello \\ de Sarti ${ }^{3}$, André Souza Pelech ${ }^{4}$
}

\begin{abstract}
${ }^{1}$ Universidade do Estado do Rio de Janeiro e Coordenação de Recursos Naturais e Estudos Ambientais do IBGE. E-mail: johana.gomes@hotmail.com

${ }^{2}$ Pesquisadora da Coordenação de Recursos Naturais e Estudos Ambientais do IBGE. E-mail: maria.f.pimenta@ibge.gov.br

${ }^{3}$ Gerente de Mapeamento de Recursos Naturais do IBGE.E-mail: therence.sarti@ibge.gov.br

${ }^{4}$ Pesquisador da Coordenação de Recursos Naturais e Estudos Ambientais do IBGE. E-mail: andre.pelech@ibge.gov.br
\end{abstract}

Artigo recebido em 20/10/2017 e aceito em 09/03/2018

\begin{abstract}
RESUMO
O mapeamento geomorfológico é um instrumento fundamental para conhecimento das formas de relevo da superfície terrestre, além de ser um relevante instrumento de base para pesquisas em diversas outras temáticas. Sendo assim, este trabalho tem como objetivo investigar as finalidades de aplicação desses produtos quando utilizados em publicações acadêmicas e, para isso, foram analisadas revistas científicas de relevância nacional e internacional publicadas entre os anos de 2006 e 2016. Neste catálogo, foram identificados artigos que contavam com um ou mais mapas geomorfológicos e, a partir dele, foram criadas categorias baseadas nos propósitos de utilização dos referidos mapas geomorfológicos, no contexto da produção acadêmica atual. Como resultado, verificou-se que atualmente o mapeamento é realizado principalmente para a caracterização morfográfica do relevo, mas também é amplamente empregado na geomorfologia aplicada a outras temáticas.
\end{abstract}

Palavras-chave: mapeamento geomorfológico; produção acadêmica; aplicações científicas.

\section{ANALYSIS OF THE BRAZILIAN GEOMORPHOLOGICAL CARTOGRAPHY APPLICATION IN ACADEMIC PRODUCTION FROM 2006 TO 2016}

\begin{abstract}
Geomorphological mapping is a fundamental tool to know and understand landforms, and it is a relevant base tool for research on several other topics, as well. The aim of this work is to investigate the application of these products when used in academic publications. For this purpose, scientific journals of national and international relevance published between the years 2006 and 2016 were analyzed. In this search, articles that had one or more geomorphological maps were identified and, from them, were created categories based on the purposes of using such geomorphological maps, in the context of current academic production. As a result, it was verified that geomorphological mapping is currently performed mainly for morphographic characterization of relief, but it is also widely used in geomorphology applied to other themes.
\end{abstract}

Key-words: geomorphological mapping; production research; scientific applications. 


\section{INTRODUÇÃO}

Os periódicos científicos são atualmente os principais meios de veiculação da produção acadêmica mundial, sendo, portanto, as forças motrizes da ciência e o viés dos paradigmas que orientam a sua evolução (SALGADO, 2008). É através deste meio de comunicação que o conhecimento é transmitido e se desenvolve, permitindo que os conceitos se consolidem e possam ser contestados; neles, também estão contidas as finalidades da ciência, seus métodos, recortes de análise e demais características.

Vitte (2009) já ressaltava a importância da análise das produções acadêmicas voltadas para a Geomorfologia; segundo o autor, "atualmente, o cenário internacional referente à produção da Geografia Física, e em especial a produção da Geomorfologia, vem merecendo um amplo debate sobre a situação da Geomorfologia na Geografia e suas relações com as ciências humanas e naturais." E ainda, de acordo com Almeida e Silva (2015), por ser uma ciência que estuda o relevo e seus processos atuantes, a Geomorfologia "fornece subsídios para identificar, registrar e analisar a evolução da paisagem", conhecimento este imprescindível nos projetos de planejamento ambiental.

Segundo Trentin (2012), “os estudos geomorfológicos podem contribuir no planejamento e na conservação dos recursos naturais, estabelecendo formas racionais de uso destes recursos", ou seja, para a gestão do território este tipo de informação torna-se essencial na fase do ordenamento. Amorim e Oliveira (2008), salientam também que estas análises permitem assinalar, em escalas locais ou mesmo regionais, categorias específicas de identificação e avaliação de impactos ambientais e avaliação de áreas de riscos e de vulnerabilidade ambiental. Frente a atual disseminação de informações geoespaciais e ampliação do acesso a representações do relevo, tais como os Modelos Digitais de Elevação (MDEs), e também com o incremento na distribuição de plataformas de Sistemas de Informações Geográficas (SIGs), pode-se observar que o meio científico vem explorando tais produtos e ferramentas para gerar mapeamentos temáticos. Sendo assim, tendo em vista o atual paradigma da Geografia Física, que visa em última análise a aplicação das análises espaciais ao planejamento ambiental, esta pesquisa buscou investigar de que forma e com que propósito os mapas geomorfológicos vêm sendo produzidos na atualidade.

Desta maneira, o presente estudo teve como escopo principal a contribuição para tal debate através da investigação da produção acadêmica recente que realiza e utiliza o mapeamento geomorfológico em suas pesquisas realizadas no território brasileiro. Também 
buscou-se compilar dados para identificar quantos e quais artigos científicos fazem uso do mapeamento do relevo, reconhecendo os autores e suas instituições, além de categorizar as produções acadêmicas selecionadas de acordo com o seu objetivo principal para, desta forma, discutir a importância do mapeamento geomorfológico no âmbito científico e no planejamento territorial.

\section{MATERIAL E MÉTODOS}

A primeira etapa de trabalho para o presente estudo foi a escolha de revistas científicas reconhecidas academicamente por publicações na área da ciência geomorfológica, e que assim possuiriam potencial para apresentarem mapeamentos geomorfológicos. Também foi feito um levantamento bibliográfico de estudos voltados para análise da produção científica na área da Geomorfologia. As revistas foram selecionadas de acordo com a sua relevância no cenário nacional e internacional e, para tal, foram analisadas sua inserção na avaliação Qualis da CAPES (Coordenação de Aperfeiçoamento de Pessoal de Nível Superior). Este é um conjunto de procedimentos utilizados por essa instituição para estratificação da qualidade da produção intelectual dos programas de pós-graduação e, desta forma, afere a qualidade dos artigos e de outros tipos de produção a partir da análise da qualidade dos veículos de divulgação, ou seja, dos periódicos científicos.

Nas então selecionadas revistas, foram analisados todos os números lançados entre os anos de 2006 a 2016, e identificou-se os artigos que elaboraram ou utilizaram mapas geomorfológicos. Este recorte temporal foi selecionado para enfatizar a produção atual deste tipo de produto. Desta forma, para o presente estudo, foram selecionados dois periódicos internacionais para análise: a revista Geomorphology, da Holanda, e a revista Earth Surface: Processes and Landforms, do Reino Unido, ambas classificadas como A1 em Geografia pela CAPES no ano de 2015, com fator de impacto 3.282 e 3.505, respectivamente. Quanto às publicações nacionais, foram escolhidos seis periódicos: dois de classificação A1 em Geografia - Sociedade e Natureza e Mercator; dois A2 - Brazilian Journal of Geology e Revista Brasileira de Geomorfologia; um periódico de classificação B1 - Revista Brasileira de Geografia Física - e um periódico de classificação B2 - Geonomos.

Os artigos encontrados foram catalogados em forma de planilha, na qual foram estabelecidas categorias de análise para a geração e análise de informações, que foram geradas ao longo do próprio trabalho de avaliação dos artigos encontrados, observando suas características. Para identificação do objetivo principal do mapeamento dos artigos 
encontrados, foi criada na planilha, a partir da observação dos próprios artigos, uma coluna de nome "finalidade" com as seguintes categorias: "caracterização", "metodologia", "evolução do relevo" e "geomorfologia aplicada", tendo essa última as subcategorias "produção agropecuária', 'planejamento territorial', 'subsídio para outras áreas temáticas' e 'risco, susceptibilidade e vulnerabilidade'. Também foi identificado o recorte espacial do mapeamento de cada artigo com a criação das seguintes categorias de recorte: "unidades de conservação", "unidades geomorfológicas", "bacias hidrográficas", "canais fluviais" e "recortes administrativos", na qual são considerados os mapeamentos que tiveram como recorte os limites dos bairros, municípios, unidades de federação e regiões, entre outros.

Por fim, foram identificados também as instituições dos primeiros autores dos artigos que apresentaram o mapeamento geomorfológico, para que se pudesse espacializar a atual produção brasileira.

\section{RESULTADOS E DISCUSSÕES}

Foram encontrados nos periódicos investigados, um total de 229 artigos que possuem mapeamento geomorfológico do território brasileiro (Tabela 1). Destes, 10 estavam presentes em publicações internacionais, 8 artigos na publicação Geomorphology e 2 no periódico Earth Surface, e nas revistas nacionais foi encontrado um maior quantitativo de publicações, com um total de 219 artigos. Este resultado evidencia a pequena inserção da discussão de metodologia e mapeamento geomorfológico brasileiro no cenário mundial, compondo apenas 4,4\% das publicações analisadas em periódicos internacionais. Nas revistas nacionais, destaca-se a 'Revista Brasileira de Geomorfologia', com 50,2\% das publicações encontradas na temática em voga no período analisado, e, em um segundo patamar, a 'Revista Brasileira de Geografia Física', com 16,2\%. Na 'Sociedade e Natureza' e 'Mercator' foram encontrados um total de 19 e 28 artigos, respectivamente, destacando os estados de Minas Gerais e Ceará no cenário nacional; o que compõe o realce às regiões Sudeste e Nordeste neste eixo de produção acadêmica.

Ao longo da história, os mapeamentos geomorfológicos foram empregados para diversos fins e aplicabilidades, utilizando-se das representações cartográficas para espacializar o seu objeto de estudo e assim melhor visualizar as formas e os processos da Geomorfologia. Por isso, aplica elementos que auxiliem na melhor compreensão da evolução e dinâmica do relevo e, como toda a representação cartográfica, variam em função do que se pretende representar e da escala desta representação. Sendo assim, buscou-se analisar a finalidade com 
a qual foram empregados os mapeamentos geomorfológicos presentes nos artigos encontrados na presente pesquisa (Tabela 2). Observou-se que a maioria deles, em um total de 94 artigos, cerca de $40 \%$ do total, utilizou o mapeamento para fazer a caracterização morfográfica do relevo da área de estudo, como acontece em Robaina et al. (2016) e Santos et al. (2007), que utilizaram o mapeamento para a espacialização de feições do relevo e também para sistematizar uma cartografia regional. Por possuir diversas abordagens - processual, estrutural e histórica - e escalas, Almeida e Silva (2015), já ressaltavam a inexistência de uma metodologia homogênea para os mapeamentos geomorfológicos a nível mundial, que surgiram em Europa do século XX.

Tradicionalmente, a caracterização do relevo era realizada por fisiografia descritiva e estática, e depois foi ganhando elementos dos processos de formação, na fase moderna da geomorfologia analítica, e hoje, por conta da emergência das geotecnologias, incorpora ainda os aspectos morfométricos. No mesmo patamar, com também cerca de $40 \%$ das publicações examinadas, estão aqueles nos quais o mapeamento é aplicado como instrumento para alcançar algum outro objetivo, ou seja, a Geomorfologia é utilizada para apoiar o estudo de outro tema ambiental. Destes, 19 artigos utilizaram o mapeamento para subsidiar o planejamento territorial, como ocorre em Junior et al. (2012) e Neto (2016), estando o relevo como base fisiografia para a definição de unidades de paisagens e para o ordenamento de uso da terra; também destaca-se o seu uso como forma de avaliar a produção agropecuária (ASSIS et al., 2016; THOMAZ, 2007).

Temas ligados a avaliação de risco, suscetibilidade e vulnerabilidade possuem também 19 registros, tais quais em Pedroso e Pereira (2011) e Fushimi (2013), o que indica mais uma vez a sua importância em estudos de integração temática. Estes autores destacam as informações da geomorfologia das suas áreas de estudos como valoroso fator biogeofísico na modelagem ambiental para o desencadeamento de processos de evolução de vertentes e possíveis desastres naturais. Também foram evidenciados, sob o aspecto ambiental, sua aplicabilidade para as práticas conservacionistas e o manejo ambiental adequado sobretudo de sistemas naturais de morfodinâmica instável e vulnerável às manifestações erosivas. $\mathrm{O}$ mapeamento geomorfológico foi utilizado ainda, em 46 periódicos, como subsídio para outras áreas, como climatologia (SIQUEIRA et al., 2012), pedologia (SOUZA \& SILVA, 2016) e recursos hídricos (ALBULQUERQUE e SOUZA, 2016). Outros 35 artigos, o que compreende $15,3 \%$ dos trabalhados avaliados, utilizaram o mapeamento da geomorfologia 
como meio de compreender a evolução do relevo, assim como em Pinheiro e Neto (2015), que correlacionaram a rede de drenagem com a ocorrência de feições erosivas, em abordagem neotectônica, e em Vasconcelos et al. (2016), que sugeriram uma morfocronologia para barreiras costeiras. Na presente pesquisa também foram encontrados mapeamentos - 14 artigos, 6,1\% - que se propunham a discutir metodologias de mapeamento (FERNADES e VALERIANO, 2013; TINÓS et al. 2014) ou estilos cartográficos para representação do relevo (RODRIGUEZ, 2009), sobressaindo a utilização de tecnologias e novos métodos.

A heterogeneidade dos mapeamentos geomorfológicos analisados ao longo de todo este trabalho também esteve presente nos recortes espaciais escolhidos para sua realização (Tabela 3), que variaram de acordo com o objetivo do autor, do objeto em questão e da abrangência geográfica. Aqueles voltados ao ordenamento e gestão em estruturas territoriais em geral apresentaram recortes administrativos, como acontece em 83 artigos ou 36,2\% do total analisado analisados, a exemplo de Garcia et al. (2012) e Silva et al. (2016). Estudos voltados para questões relacionadas à água, erosão e pressão do homem sobre o ambiente, em geral apresentaram como recorte espacial as bacias hidrográficas, tais quais em Franco e Santos (2015) e Brito e Leite (2015), o que compôs 34,1\% dos artigos encontrados. Outros 19 artigos, ou 8,3\%, utilizaram como categoria de recorte feições relacionadas aos processos de canais fluviais, como ocorre em Marçal (2013) e Morais et al. (2016), estudos específicos em Geomorfologia Fluvial. Recortes de feições geomorfológicas como serras, depressões e dunas estão presentes em 31 periódicos, ou 13,5\% do total, e outros como Unidades de Conservação (9), folhas cartográficas (3) e outros outros (6) somaram cerca de $20 \%$ da produção acadêmica em questão.

Por último, analisando as instituições dos primeiros autores e as respectivas macrorregiões brasileiras nas quais são localizadas, verifica-se uma concentração de periódicos que contêm mapeamentos geomorfológicos nas Regiões Sudeste, com 92 periódicos, e Nordeste, com 53; em seguida, aparece a Região Sul com 39 instituições. Instituições que possuem abrangência nacional, como o INPE e a EMBRAPA, produziram 11 artigos. Por fim, instituições internacionais que realizaram parcerias com instituições brasileiras somaram 7 artigos. 
Tabela 1 - Quantidade de artigos por periódicos.

\begin{tabular}{ccccc}
\hline Perídicos & Quantidade de artigos & $\%$ & Classificação & Origem \\
\hline Earth surface processes and landforms & 2 & 0,9 & $\mathrm{~A} 1$ & Reino Unido \\
Geomorphology & 8 & 3,5 & $\mathrm{~A} 1$ & Holanda \\
Mercator & 28 & 12,2 & $\mathrm{~A} 1$ & Ceará \\
Sociedade e Natureza & 19 & 8,3 & $\mathrm{~A} 1$ & Minas Gerais \\
Brazilian Journal of Geology & 14 & 6,1 & $\mathrm{~A} 2$ & São Paulo \\
Revista Brasileira de Geomorfologia & 115 & 50,2 & $\mathrm{~A} 2$ & São Paulo \\
Revista Brasileira de Geografia Física & 37 & 16,2 & $\mathrm{~B} 1$ & Pernambuco \\
Geonomos & 6 & 2,6 & $\mathrm{~B} 2$ & Minas Gerais \\
TOTAL & 229 & 100,0 & & \\
\hline
\end{tabular}

Tabela 2-Quantidade de artigos por finalidade.

\begin{tabular}{ccc}
\hline Finalidade & Quantidade de artigos & $\%$ \\
\hline Caracterização & 94 & 41,0 \\
Geomorfologia Aplicada & 86 & 37,6 \\
Evolução do relevo & 35 & 15,3 \\
Metodologia & 14 & 6,1 \\
TOTAL & 229 & 100,0 \\
\hline
\end{tabular}

Tabela 3 - Quantidade de artigos por recorte espacial.

\begin{tabular}{ccc}
\hline Categorias de Recorte & Quantidade de artigos & $\%$ \\
\hline Bacia Hidrográfica & 78 & 34,1 \\
Folha cartográfica & 3 & 1,3 \\
Recorte administrativo & 83 & 36,2 \\
Canais Fluviais & 19 & 8,3 \\
Unidade de conservação & 9 & 3,9 \\
Feições geomorfológicas & 31 & 13,5 \\
Outros & 6 & 2,6 \\
TOTAL & 229 & 100,0 \\
\hline
\end{tabular}

\section{CONSIDERAÇÕES FINAIS}

Algumas questões importantes podem ser levantadas diante dos números apontados nesta pesquisa: é necessário destacar, por exemplo, a grande quantidade de artigos cuja finalidade era a caracterização do relevo, totalizando cerca de $40 \%$ dos artigos pesquisados. Este número pode indicar a ausência de mapeamento geomorfológico adequado em escalas de maior detalhe, e essas iniciativas demonstram a necessidade e a importância de se caracterizar o relevo em um país de grandes dimensões como o Brasil. 
A grande quantidade de artigos encontrados em apenas um periódico - a Revista Brasileira de Geomorfologia - sugere que a produção acadêmica de um determinado tema pode ser potencializada através de periódicos especializados como este, que teve sua primeira edição no ano 2000. Também é importante destacar a grande produção acadêmica na categoria 'geomorfologia aplicada', especialmente nas classificadas como 'subsídio para outras áreas', que representam mais de $50 \%$ dos estudos da categoria. Este fato ressalta a importância da ciência geomorfológica como base de compreensão para diversos processos e fenômenos naturais.

As outras subcategorias, apesar de serem percentualmente menos abordadas, possuem um significativo número de artigos que mostram a inserção da geomorfologia em estudos de caráter integrado na esfera ambiental - representados pela subcategoria 'risco, susceptibilidade e vulnerabilidade' - e na esfera de planejamento territorial.

\section{REFERÊNCIAS}

ALBUQUERQUE, E. L. S; DE SOUZA, M. J. N. Condições ambientais e socioeconômicas nas bacias hidrográficas costeiras do setor leste metropolitano de Fortaleza, Estado do Ceará. Revista Brasileira de Geografia Física, Recife, v. 9, n. 1, p. 110-124, 2016.

ALMEIDA, R. M. R.; SILVA, T. M. A importância dos mapeamentos geomorfológicos na ciência. Juiz de Fora: Revista de Geografia do PPGEO/UFJF, 2015.

AMORIM, R. R.; OLIVEIRA, R. C. de. As unidades de paisagem como uma categoria de análise geográfica: o exemplo do município de São Vicente-SP. Sociedade e Natureza, 2008. AMORIM, R. R.; OLIVEIRA, R. C. de. Zoneamento ambiental, subsídio ao planejamento no uso e ocupação das terras da costa do descobrimento. Mercator, 2013.

ASSIS. T.; JÚNIOR, A. F. C.; MARTINS, E. de S.; Relações entre o relevo e os agroecossistemas na ecorregião Paraná-Guimarães. Revista Brasileira de Geografia Física, 2016.

BRITO, D. S. de; LEITE, E. F.; Aplicação da metodologia do DFC para avaliar o potencial erosivo natural da bacia hidrográfica do Rio Água Suja, Tocantins (Brasil). Revista Brasileira de Geografia Física, 2015.

FERNANDES, P. J. F.; VALERIANO, M. M. Relações Entre Dados Srtm E Classes Geomorfológicas Do Projeto RADAMBRASIL. Revista Brasileira de Geomorfologia, v. 14, p. 357, 2014. 
FERREIRA, A. T. da S. et al. Mapeamento geomorfológico de detalhe para delimitação de áreas de preservação permanentes. Revista Brasileira de Geomorfologia, 2016.

FRANCO, A. C. V.; SANTO, M. A. D. Contribuição da morfometria para o estudo das inundações na sub-bacia do Rio Luis Alves. Mercator, 2015.

FUSHIMI M., NUNES J. O. R., NAKAMURA R. Y., TAKATA L. T. O. Vulnerabilidade ambiental e aplicação de técnicas de contenção aos processos erovisos lineares em áreas rurais do município de presidente prudente. Revista Brasileira de Geomorfologia, 2013.

GARCIA, P. M.B; SOBREIRA, F. G. S.; MOURA, A. C. M. 2012. Potencial de expansão e ocupação urbana no município de Timóteo - MG. Revista Brasileira de Geociências, 2012.

JÚNIOR M., PEREIRA P.; MARQUES, F. S. E. M.; CARNEIRO, João Álvaro; VASCONCELOS, V. V.; NOVAES, Leandro Arb D’abreu; ROSA, S. A. G.. Gestão geoambiental de bacias hidrográficas: os sistemas geológicos como fase inicial de decisão para uso da terra. Revista Brasileira de Geociências, v. 42, p. 96-113, 2012.

MARCUZZO, F. F. N.; OLIVEIRA, N. de L.; CARDOSO, M. R. D. Tendência do Número de Dias de Chuva no Estado do Mato Grosso do Sul e Sua Relação com o Fenômeno ENOS. Revista Brasileira de Geografia Física, 2012.

MARÇAL, M. S. Análise das Mudanças Morfológicas em Seções Transversais ao Rio Macaé - RJ. Revista Brasileira de Geomorfologia, v. 14, p. 59-68, 2013.

MORAIS, EDUARDO SOUZA DE; SANTOS, M. L.; CREMON, E. H.; STEVAUX, J. C. Floodplain evolution in a confluence zone: Paraná and Ivaí rivers, Brazil. Geomorphology (Amsterdam), V. 257, P. 1-9, 2016.

NETO, M. R. Geomorfologia e geossistemas: influências do relevo na definição de unidades de paisagem no maciço alcalino do Itatiaia (MG/RJ). Revista Brasileira de Geomorfologia (Online), São. Paulo, v.17, n.4, (Out-Dez) p.729-742. 2016.

OLIVEIRA, K. Q. R.; SALGADO, A. A. R. Geomorfologia brasileira - panorama geral da produção nacional de alto impacto no quinquênio 06-10. Revista Brasileira de Geomorfologia, 2013.

PEDROSA, A.; PEREIRA, A. (2011) - A integração das formações superficiais na modelação e cartografia do risco geomorfológico: o caso da Serra do Marão, Soc. \& Nat, Uberlândia, ano $23, \mathrm{n}^{\circ} 3$.

PINHEIRO, M. R.; NETO, J. P. de Q. Neotectônica e evolução do relevo da região da serra de são pedro e do baixo rio piracicaba. Revista Brasileira de Geomorfologia, 2015. 
RIBEIRO, A. dos S. et al. Vulnerabilidade ambiental à erosão hídrica em uma sub bacia hidrográfica pelo processo analítico hierárquico. Revista Brasileira de Geografia Física, 2016.

ROBAINA, L. E. de S.; TRENTIN, R.; LAURENT, F. Compartimentação do estado do Rio Grande do Sul do Brasil, através do uso de geomorphons obtidos em classificação topográfica automatizada. Revista Brasileira de Geomorfologia, 2016.

RODRIGUES, S. C. Cartografia e simbologia geomorfológica - evoluindo da cartografia tradicional para o uso de simbologia digital. Revista Brasileira de Geomorfologia, 2009.

SALGADO, A. A. R.; BIAZINI, J.; HENNING, S. Geomorfologia Brasileira - Panorama geral da produção nacional no início do século XXI. Revista Brasileira de Geomorfologia, 2008.

SANTOS, L. J. C. et al, Mapeamento da vulnerabilidade geoambiental do estado do Paraná. Revista Brasileira de Geociências, 2007.

SILVA, M. T. A Geodiversidade como subsídio à revisão de Planos Diretores. Revista Brasileira de Geografia Física, 2016.

SILVEIRA, R. M.P.; SILVEIRA, C. T. da.; OKA-FIORI, C. Emprego de técnicas de inferência espacial para identificação de unidades de relevo. Revista Brasileira de Geomorfologia, 2014.

SIQUEIRA, G. M.; BEZERRA, J. M.; VIEIRA, S. R.; CAMARGO, M. B. P.. Zoneamento de parâmetros climáticos no Estado de São Paulo (Brasil) utilizando técnicas de geoestatística. Revista Brasileira de Geografia Física, v. 03, p. 612-629, 2012.

SOUZA, A. C. Da C.; SILVA, M. L. Geoprocessamento aplicado ao levantamento de solos no município de Inconfidentes-MG. Revista Brasileira de Geografia Física, 2016.

TINÓS T. M., FERREIRA M. V., RIEDEL P. S., ZAINE J. E. Aplicação E Avaliação De Metodologia De Classificação Automática De Formas De Relevo, Revista Brasileira de Geomorfologia, 2014.

THOMAZ, E. L.. Compartimentos geomorfológicos e produção de milho em agricultura de subsistência, Guarapuava-PR: avaliação exploratória. SOCIEDADE \& NATUREZA (UFU. ONLINE), v. 19, p. 45-54, 2007.

TRENTIN, R.; SANTOS, L. J. C.; ROBAINA, L. E. de S. Compartimentação geomorfológica da bacia hidrográfica do Rio Itu - Oeste do RS - BR. Sociedade e Natureza, 2012. 
Revista de Geografia (Recife) V. 35, No. 4 (especial XII SINAGEO), 2018

VASCONCELOS, S. C. et al. Gênese e morfodinâmica das barreiras arenosas no flanco norte do delta do Rio Paraíba do Sul. Revista Brasileira de Geomorfologia, 2016.

VITTE, A. C.; NIELLMAN, R. S. Uma introdução à história da geomorfologia no Brasil: a contribuição de Aziz Nacib Ab’Saber. Revista Brasileira de Geomorfologia, 2009. 